\title{
DEFINIÇÃO DE METADADOS PARA O REPOSITÓRIO DE OBJETOS DE APRENDIZAGEM DA EAD - UFSC
}

\author{
Projeto desenvolvido junto ao Departamento de \\ EAD/UFSC - 2007-2008.
}

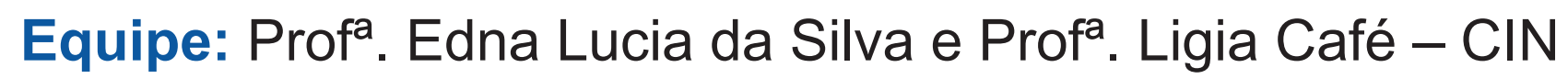

Colaboração: Prof. Ricardo Silveira e equipe - INE

Equipe do NPD

Coordenação Geral: Profa . Araci Hack Catapan - EADUFSC 


\section{OBJETIVO DO PROJETO}

Definir parâmetros para a implantação de um repositório aprendizagem, para objetos de compartilhamento de recursos didáticos no ambiente Moodle UFSC.

Envolvendo:

Definição de padrões de funcionamento;

Definição de padrões de metadados. 


\section{OBJETO DE APRENDIZAGEM}

- Definição: Qualquer arquivo digital (texto, imagem ou vídeo) que possa ser usado para facilitar ou promover a aprendizagem.

- Delimitação: Material criado ou adaptado por professores com objetivo educacional para ser utilizado como recurso didático. 


\section{OBJETOS DE APRENDIZAGEM (OA)}

- Segundo Wiley (2002)

são entidades digitais disponibilizadas na Internet, significando que todas as pessoas podem alcançá-las e usá-las simultaneamente. Engloba, nessa definição, qualquer recurso digital que possa ser (re)utilizado como suporte no processo de aprendizagem. 


\section{OBJETOS DE APRENDIZAGEM (OA)}

- Recomendação para criação de OA:

- Os objetos de aprendizagem devem ser criados em pequenas unidades, com o propósito de maximizar o número de situações educativas em que se podem utilizar e reutilizar tais recursos. 


\section{CARACTERÍSTICAS DOS OA}

- Acessibilidade: devem possuir uma identificação padronizada que garanta a sua recuperação (metadados);

- Reusabilidade: devem ser desenvolvidos de forma a compor diversas unidades de aprendizagem;

- Interoperabilidade: devem ser criados para serem operados em diferentes plataformas e sistemas;

- Portabilidade: devem ser criados com a possibilidade de se mover e se abrigar em diferentes plataformas;

- Durabilidade: devem permanecer intactos perante as atualizações de software ou hardware. 


\section{REPOSITÓRIO DE OBJETOS DE APRENDIZAGEM}

- Definição: Espaço de compartilhamento de recursos didáticos para serem usados com objetivos educacionais.

- Filosofia: auto-arquivamento e colaboração.

- Funcionamento: similar aos sistemas de compartilhamento de músicas, como por exemplo: Kazaa. 


\section{REPOSITÓRIOS NO EXTERIOR}

Ariadne (Alliance of Remote Instructional

Authoring and Distribution Network for

Europe) -1996

4.500 objetos de aprendizagem (2008)

Abrangência: várias áreas de conhecimento

Armazena metadados e OA

Padrão de metadados: IEEE-LOM 


\section{REPOSITÓRIOS NO EXTERIOR}

Edna (Education Network Australia) - 1996

20.000 objetos de aprendizagem (2008)

Abrangência: áreas de Educação e Treinamento para Educação escolar, infantil, adulta e ensino superior.

Armazena metadados e OA

Padrão de metadados: próprio baseado em DC 


\section{REPOSITÓRIOS NO EXTERIOR}

MERLOT (Multimedia Educational Resource for Learning and Online Teaching) - 1997

Consórcio mantido por várias entidades, principalmente dos Estados Unidos e Canadá e coordenado pela California State University

19.043 Objetos de aprendizagem (2008)

Abrangência: Artes, Negócios, Educação, Humanidades, Matemática e Estatística, Ciência e Tecnologia e Ciências Sociais.

Armazena somente os metadados. 


\section{REPOSITÓRIOS NO EXTERIOR}

\section{Wisconsin}

Desenvolvido pela Wisconsin Technical College System (WTCS) - Inglaterra

2316 objetos de aprendizagem (2008)

Abrangência: área: Educação de adultos, Inglês como segunda língua, Ensino Técnico, Negócios, Serviços de saúde e desenvolvimento profissional.

Padrão de metadados: próprio. 


\section{REPOSITÓRIOS NO EXTERIOR}

\section{Universia}

Repositório de metadados: Biblioteca Universia de Recursos de Aprendizagem (BURA)

3.368.603 objetos de aprendizagem 80 coleções dispersas pelo mundo (2008).

Abrangência: várias áreas

Padrão de metadados: SCORM-IMS 


\section{REPOSITÓRIOS NO EXTERIOR}

RIVED/MEC (Rede Internacional Virtual de Educação)

Projeto de cooperação entre Brasil, Venezuela e Peru.

172 objetos de aprendizagem (2008).

Abrangência: Ciências e Matemática - Ensino Médio

Padrão de metadados: no início IMS e EML(1). Depois incorporou também o Dublin Core. Atualmente não há um padrão único definido.

(1)Educational Modelling Language é um padrão livre para criação e administração de processos de aprendizagem, similar ao SCORM, desenvolvido pela Universidade Aberta da Holanda (OUNL). 


\section{REPOSITÓRIOS NO BRASIL}

CESTA

Coletânea de Entidades de Suporte ao uso de Tecnologia na Aprendizagem

UFRGS

Padrão de metadados: IEEE-LOM 


\section{TIPOS DE REPOSITÓRIOS}

- 1) aqueles que contêm tanto os recursos/objetos de aprendizagem como os metadados desses objetos (Exemplo: Wisconsin On-line Resource Center);

- 2) aqueles que contêm somente os metadados dos recursos/objetos de aprendizagem e os recursos/objetos encontram-se armazenados em outro lugar no qual o repositório pode localizá-lo, a partir das informações dos metadados e por uma ferramenta adequada para isso (Exemplo: Merlot). 


\section{METADADOS}

- Nos repositórios, os objetos de aprendizagem são descritos por meio de metadados.

- Definição:

- representam a informação estruturada que descreve, explica e torna possível a localização e a recuperação dos OAs nos repositórios.

- Função:

- facilitam o compartilhamento dos objetos pois definem um conjunto de elementos que permitem identificar as principais características dos recursos disponíveis visando a sua recuperação e reutilização. 


\section{INSTITUIÇÕES E PADRÕES DE METADADOS RELACIONADOS À EAD}

Instituição

Aviation Industry [Computer Based Training] Committee (AICC)

Centre Européen de Normalisation /Information Society Standarization System - Learning Technologies WorkShop (CEN/ISSS LTWS)

Dublin Core Metadata Initiative (DCMI)

\section{Realização}

Responsável pelo desenvolvimento do AICC Guidelines and Recommendations (AICC AGRs). URL: http://www.aicc.org/

Responsável pela especificação Learning Objet Metadada (LOM) na Europa e o desenvolvimento do Educational Modelling Language (EML). URL:

http://www.cenorm.be/isss/ .

Grupo responsável pelo desenvolvimento do Dublin Core. URL: http://dublincore.org/ 


\section{INSTITUIÇÕES E PADRÕES DE METADADOS RELACIONADOS À EAD}

\begin{tabular}{|c|c|}
\hline Instituição & Realização \\
\hline $\begin{array}{l}\text { Institute of Electrical and Electronics } \\
\text { Engineers (IEEE) - Learning } \\
\text { Technology Standards Committee } \\
\text { (LTSC) }\end{array}$ & $\begin{array}{l}\text { Responsável pelo desenvolvimento da } \\
\text { especificação Learning Object Metadata } \\
\text { (LOM). URL: } \underline{\text { http://ltsc.ieee.org }}\end{array}$ \\
\hline $\begin{array}{l}\text { Instructional Management System } \\
\text { Global Learning Consortium Inc (IMS) }\end{array}$ & $\begin{array}{l}\text { Responsável por especificações para a } \\
\text { interoperabilidade das tecnologias de } \\
\text { aprendizagem incluem: metadados, } \\
\text { gestão de conteúdos e acessibilidade. } \\
\text { URL: http://www.imsproject.org/ }\end{array}$ \\
\hline $\begin{array}{l}\text { International Standards Organisation } \\
\text { (ISO) }\end{array}$ & $\begin{array}{l}\text { Desenvolvimento da ISO-19788-2 } \\
\text { Information Technology-Learning, } \\
\text { Education, and Training- Metadata for } \\
\text { Learning Resources. É a entidade que } \\
\text { tem a responsabilidade máxima } \\
\text { mundialmente para o estabelecimento de } \\
\text { padrões. URL: www.iso.ch/ }\end{array}$ \\
\hline
\end{tabular}




\section{PADRÕES DE METADADOS: Dublin Core}

-Desenvolvido pelo Dublin Core Metadata Initiative(DCMI).

-Descreve de forma simples qualquer tipo de recurso.

-Adotado por: vários repositórios

-Previsão 2007-2008: Perfil de aplicação do Dublin Core para descrever objetos digitais educacionais. 


\section{Dublin Core}

\section{Atributos}

Identificador

Colaborador

Cobertura

Criador

Data

Descrição

Formato

Linguagem

Publicador

Relação

Direitos

Fonte

Assunto

Título

Tipo de recurso

\section{Descrição}

Identificação não ambígua do recurso dentro de um dado contexto.

Entidade responsável pela contribuição ao conteúdo do recurso.

Extensão ou cobertura espaço-temporal do conteúdo do recurso.

Entidade principal responsável pela elaboração do conteúdo do recurso.

Entidade principal responsável pela elaboração do conteúdo do recurso.

Descrição sobre o conteúdo do recurso.

Manifestação física ou digital do recurso.

Idioma do conteúdo intelectual do recurso.

Instituição responsável pela difusão do recurso.

Uma referência a outro recurso que se relaciona com o recurso em questão.

Informações sobre os direitos do recurso e de seu uso.

Uma referência para um outro recurso que tenha dado origem ao presente recurso.

Assunto referente ao conteúdo do recurso.

Título dado ao recurso.

A natureza ou gênero do conteúdo do recurso. 


\section{PADRÕES DE METADADOS: Learning Object Metadada (LOM)}

-Desenvolvido pelo Institute of Electrical and Electronics. Engineers (IEEE)

-Adotado por: LearnAlberta Portal, Universia, COLIS, iLumina, Lydia, Merlot, SMETE, HEAL (Health Education Assets Library). 


\section{Learning Object Metadata (LOM)}

Caracteristicas

Gerais

Ciclo de vida

Meta-metadados

Técnicas

Educacionais

Direitos

Relação com

outros recursos

Observações

Classificação
Reúnem as características gerais sobre o objeto de aprendizado; tais como: identificador (catálogo, entrada), título, idioma, descrição, palavra-chave, cobertura, estrutura, nível de agregação.

Descrevem a evolução, o estado atual, e as diversas contribuições, tais como: versão, status, contribuintes (papel, entidade, data).

Descrevem os metadados que estão sendo utilizados, tais como: Identificador (catalogo, entrada), contribuintes (papel, entidade e data), esquema de metadados, Linguagem.

Reúnem aspectos técnicos necessários para utilizar o objeto de aprendizado, bem como, suas características próprias, tais como: formato, tamanho, localização, requisitos , comentários sobre instalação, requisitos para outras plataformas, duração.

Descrevem aspectos educacionais e pedagógicos associados, tais como: tipo de interatividade, tipo de recurso de aprendizagem, nível de interatividade, densidade semântica, papel do usuário final, contexto, faixa etária, dificuldade, tempo previsto para aprendizagem, descrição e linguagem.

Relatam condições de uso e aspectos de propriedade intelectual, tais como custo, direito de cópia e outras restrições, descrição.

Descrevem como este objeto de aprendizado está relacionado com outros objetos de aprendizado, tais como; tipo e recurso (identificador -catálogo e entrada e descrição.

Reúnem comentários sobre o uso educacional do objeto de aprendizado e dados sobre a autoria dos comentários, tais como: entidade, data, descrição.

Descrevem como um objeto de aprendizado se enquadra em um sistema de classificação 


\section{PADRÕES DE METADADOS:}

\section{Information Technology-Learning,}

Education, and Training Metadada for Learning Resources (ISO-19788-2)

-Em desenvolvimento pela ISO.

-Atualmente é objeto de estudo pelo Comitê Técnico ISO/IEC JTC1, Information Technology, Subcomitê SC36, Information Technology for Learning, Education and Training.

-Baseia-se no LOM da IEE, aprimorando seus parâmetros de descrição.

-Divide-se em duas partes: Parte1 - Estrutura; Parte 2 - Elementos de dados 


\section{ISO/IEC 19788-2}

\section{Segmentos Elementos}

\section{Descrição}

Ciclo de vida

Registro

Instanciação

Pedagógicos

Direitos

Relação com

outros recursos

Observações/ anotações

Classificação
Reúnem as características gerais sobre o recurso de aprendizagem, tais como: identificador, título, idioma, descrição, tipo de recurso, cobertura, estrutura, nível de agregação, duração.

Descrevem a evolução, o estado atual, e as diversas contribuições feitas ao recurso, tais como: versão, status, contribuintes (papel, entidade, data).

Fornece dados referentes ao: identificador, repositório original, data das atualizações, contribuintes (papel, entidade, data)., perfil (nome, identificação), idioma.

Definem aspectos e características técnicas, tais como: formato, tamanho, localização, requisitos técnicos.

Descrevem aspectos de aprendizagem e pedagógicos associados ao: contexto (audiência, idade mínima e máxima, usuário final, idioma, tipo de instrumento pedagógico, descrição pedagógica, dificuldade, tempo necessário), ao tipo e ao nível de interatividade, à densidade semântica.

Relatam condições de uso e aspectos de propriedade intelectual, identificando preço, direitos de propriedade e uso.

Descrevem como um objeto de aprendizagem está relacionado com outros objetos de aprendizagem, mostrando: tipo de relacionamento e recurso relacionado (identificador e descrição)

Reúnem comentários sobre o uso educacional do recurso e dados sobre a autoria dos comentários, tais como: participações (papel, entidade, data), descrição.

Descrevem como um recurso se enquadra em um sistema de classificação particular, indicando: propósito, tipo, fonte da nomenclatura, caminho/trajeto da nomenclatura(identificador e entrada), descrição do sistema de classificação ou palavras-chave. 


\section{RECOMENDAÇÕES PARA CRIAÇÃO DE REPOSITÓRIOS:}

- Necessidade de definição do perfil de aplicação dos metadados de acordo com o interesse dos usuários (professores autores ou adaptadores dos objetos/recursos);

- Estudo da modelagem do repositório visando atender aos seus propósitos: compartilhar objetos de aprendizagem criados ou adaptados pelos professores com objetivos educacionais;

- Envolvimento de equipes multidisciplinares: professores, bibliotecários, analistas de sistemas, designers, etc... 